\title{
Cultivo de soja sob diferentes densidades de semeadura e arranjos espaciais
}

\author{
Simério Carlos Silva Cruz ${ }^{1}$, Darly Geraldo de Sena Junior ${ }^{1}$, Danilo Marcelo Aires dos \\ Santos $^{1}$, Leandro Oliveira Lunezzo ${ }^{1}$, Carla Gomes Machado ${ }^{1}$ \\ ${ }^{1}$ Universidade Federal de Goiás - UFG, Campus Jataí - CAJ, Jataí, Goiás, Brasil. E-mail: simerio_cruz@ yahoo.com.br, \\ darly.sena@gmail.com,dmaires@hotmail.com, carlagomesmachado@gmail.com
}

Recebido: 23/09/2015; Aceito: 25/12/2015.

\section{RESUMO}

A produtividade é definida pela interação entre a planta, ambiente e manejo. Dentre as práticas de manejo destacam-se a densidade de semeadura e o espaçamento entrelinhas. Objetivou-se com este trabalho avaliar o efeito de densidades e arranjos de plantas no desenvolvimento vegetativo e produtividade de grãos de soja. $\mathrm{O}$ delineamento experimental foi de blocos casualizados com quatro repetições em esquema de parcelas subdivididas. Nas parcelas foram alocados dois arranjos espaciais: convencional $(45 \mathrm{~cm}$ entre fileiras) e fileira duplas $(65 \mathrm{~cm}$ entre uma fileira dupla e outra e $25 \mathrm{~cm}$ entre as linhas dentro da fileira dupla). Nas subparcelas foram alocadas cinco densidades de semeadura $\left(7,10,15,19\right.$ e 22 sementes $\left.\mathrm{m}^{-1}\right)$. Cada subparcela foi composta por oito linhas com 5,0 m de comprimento. A cultivar utilizada foi a ANTA 82, com ciclo de aproximadamente 115 dias e hábito de crescimento semi-determinado. O arranjo espacial em fileiras duplas proporciona redução na altura das plantas, porém não interfere na produtividade de grãos de soja. O aumento da densidade de semeadura resulta em aumento da produtividade de grãos da soja independente do arranjo espacial entre plantas utilizado.

Palavras-chave: Glycine max (L.) Merrill, arranjo espacial, hábito de crescimento.

\section{Soybean cropping under different plant densities and spatial arrangements}

\begin{abstract}
Crop yield is defined by the interaction of plant, environment and management. In management practices highlights the sowing density and row spacing. The objective of this study was to evaluate the effect of plant densities and arrangements on growth and soybean yield. The experiments were conducted using a split plot randomized block design with four replications. In plots were allocated two arrangements: conventional (45 cm between rows) and twin rows ( $65 \mathrm{~cm}$ between a twin rows and $25 \mathrm{~cm}$ within the twin rows). In the split plot were allocated five sowing density $\left(7,10,15,19\right.$ e 22 seeds $\left.\mathrm{m}^{-1}\right)$. Each split plot consisted of eight lines with $5.0 \mathrm{~m}$ long. The cultivar used was ANTA 82, with a cycle of about 115 days and semi-determinate growth habit. The spatial arrangement in twin rows provides a reduction in plant height, but does not affect soybean grain yield. Increased sowing density results in increases on the soybean yield independent of spatial arrangement used.
\end{abstract}

Key words: Glycine $\max (\mathrm{L}$.) Merrill, row spacing, growth behavior. 


\section{Introdução}

A soja [Glycine max (L.) Merrill] é uma das principais culturas oleaginosas cultivadas no mundo. Sua composição química com alto teor proteico proporciona múltiplas aplicações na alimentação humana e animal. A cultura tem um importante papel socioeconômico para o agronegócio brasileiro devido ao seu elevado potencial produtivo nas diferentes regiões. Além disso, a soja é matéria-prima indispensável para impulsionar diversos complexos agroindustriais, tais como as indústrias de sementes, fertilizantes, agrotóxicos e máquinas agrícolas (MAUAD et al., 2010).

Alcançar a máxima lucratividade em uma lavoura comercial de soja é o principal objetivo de todos os produtores, e para isso, juntamente com o clima favorável, várias técnicas de manejos são empregadas. Dentre essas técnicas podemos destacar o controle de insetos, doenças e plantas daninhas, o preparo conservacionista do solo, o uso eficiente de corretivos e fertilizantes, a escolha de cultivares mais adaptadas para a região, sementes de boa qualidade e o arranjo espacial de plantas.

Para aumentar a produtividade da soja é necessário a utilização de novas técnicas e o aperfeiçoamento das que estão sendo utilizadas, principalmente as que interferem nos componentes morfológicos e de produção. Dentre as técnicas citadas, a associação de arranjos espaciais e população de plantas, tem se destacado como ferramentas potenciais para o aumento da produtividade (BRACHTVOGEL et al., 2009).

A soja apresenta característica de alta plasticidade, que consiste na capacidade de se adaptar às condições ambientais e de manejo, por meio de modificações na morfologia e nos componentes de rendimento, a fim de adequá-los ao espaço disponível e à condição de competição imposta pelo arranjo de plantas (PIRES et al., 2000).

Modificações no arranjo de plantas têm sido tema de estudos em diversas regiões produtoras de soja tanto em regiões produtoras no Brasil, quanto nos Estados Unidos da América (EUA) (PIRES et al., 2000; TOURINO et al., 2002; BRUNS, 2011). Os resultados estão associados à alta capacidade de adaptação da cultura e às diversas condições ambientais e de manejo, tais como o aumento de população de plantas e as mudanças no espaçamento entre linhas (PIRES et al., 1998).

A densidade de semeadura além de determinar o arranjo das plantas no ambiente em que se encontra pode influenciar no crescimento das plantas de soja (MARTINS et al., 1999). Assim, a densidade de semeadura interfere na competição inter e intraespecífica por recursos do solo, especialmente por luz, água e nutrientes, além de provocar mudanças morfofisiológicas nas plantas, como altura de porte e engalhamento (ARGENTA et al., 2001).

Nos EUA a semeadura em fileira dupla já é utilizada com frequência no estado do Mississipi (BRUNS, 2011). Os mesmos autores destacam que o arranjo de plantas em fileira dupla proporciona melhor penetração de luz e produtos fitossanitários no dossel, melhorando a taxa fotossintética, o controle de plantas daninhas, a prevenção de doenças fúngicas, a sanidade e a longevidade das folhas próximas ao solo, o que pode acrescentar na produtividade de grãos.

Considerando a hipótese de que as plantas de soja cultivadas em fileira dupla apresentam maior capacidade de aproveitamento da luminosidade pelas folhas da parte inferior do dossel e em função disso a população ótima é modificada, o objetivo do trabalho foi avaliar o efeito da associação do arranjo espacial e população de plantas no desenvolvimento vegetativo e produtividade de grãos de soja.

\section{Material e Métodos}

O experimento foi conduzido no município de Jataí, GO, no período de outubro de 2013 a fevereiro de 2014, na área experimental da Universidade Federal de Goiás, Regional Jataí, cujas coordenadas geográficas são $17^{\circ} 53^{\prime} \mathrm{S}$ e $52^{\circ} 43^{\prime} \mathrm{W}$ e $680 \mathrm{~m}$ de altitude. O solo predominante na área é o Latossolo Vermelho distroférrico (EMBRAPA, 2006). Os dados de precipitação e temperatura média durante a condução do experimento, são apresentados na Figura 1.

O delineamento experimental foi de blocos casualizados com quatro repetições em esquema de parcelas subdivididas. Nas parcelas foram alocados dois arranjos espaciais: convencional (45 cm entre fileiras) e fileira duplas ( $65 \mathrm{~cm}$ entre uma fileira dupla e outra e 25 $\mathrm{cm}$ entre as linhas dentro da fileira dupla). Nas subparcelas foram alocadas cinco densidades de semeadura $\left(7,10,15,19\right.$ e 22 sementes $\left.\mathrm{m}^{-1}\right)$. Cada parcela foi composta por oito linhas com 5,0 m de comprimento. Foi considerado como área útil as quatro linhas centrais desprezando-se $0,5 \mathrm{~m}$ de cada extremidade, totalizando uma área de $7,2 \mathrm{~m}^{2}$. A cultivar utilizada foi a ANTA 82, com ciclo de aproximadamente 115 dias e hábito de crescimento semideterminado.

Antes da instalação do experimento, foi realizada a coleta de amostra de solo, na profundidade de $0-20 \mathrm{~cm}$, para análise química (Tabela 1) conforme metodologia descrita em Embrapa (2009), a qual foi utilizada para recomendação de calcário e das doses de fósforo e potássio. 


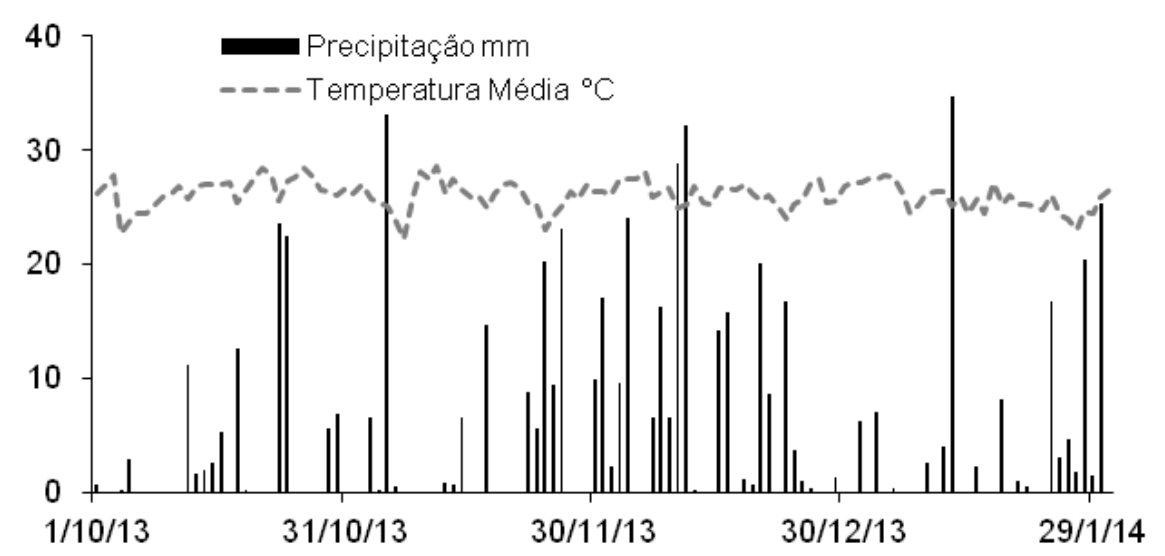

Figura 1. Precipitação pluvial e temperatura média durante a condução do experimento, Regional Jataí da UFG, safra 2013/14.

Tabela 1. Caracterização química do solo na camada de 0-20 cm, amostrado antes da instalação do experimento

\begin{tabular}{|c|c|c|c|c|c|c|c|}
\hline $\mathrm{pH}\left(\mathrm{CaCl}_{2}\right)$ & M.O. & P (Mehlich-1) & $\mathrm{K}$ & $\mathrm{Ca}$ & $\mathrm{Mg}$ & $\mathrm{H}+\mathrm{Al}$ & CTC \\
\hline & $\mathrm{g} \mathrm{dm}^{-3}$ & $\mathrm{mg} \mathrm{dm}^{-3}$ & ---- & $-\cdots$ & $\mathrm{ll}_{\mathrm{c}} \mathrm{dn}$ & $-\cdots$ & --- \\
\hline 5,0 & 23 & 8,7 & 0,8 & 29 & 22 & 26 & 78 \\
\hline
\end{tabular}

M.O.: matéria orgânica.

As sementes foram tratadas com $200 \mathrm{~mL}$ do fungicida Derosal Plus (carbendazim + tiram), $300 \mathrm{~mL}$ do inseticida Cropstar (imidacloprido + tiodicarbe) e $200 \mathrm{~mL}$ de inoculante para $100 \mathrm{~kg}$ de sementes.

Foi realizada adubação em semeadura com $120 \mathrm{~kg}$ $\mathrm{ha}^{-1}$ de $\mathrm{P}_{2} \mathrm{O}_{5}$ e $60 \mathrm{~kg} \mathrm{ha}^{-1}$ de $\mathrm{K}_{2} 0$, misturados e distribuídos no fundo do sulco. As fontes utilizadas foram superfosfato simples e cloreto de potássio, respectivamente.

A soja foi semeada no dia 28 de outubro de 2013. As sementes foram distribuídas manualmente no sulco de semeadura, com auxílio de gabaritos de madeira, de acordo com cada tratamento.

No dia 2 de novembro do mesmo ano foram aplicados 2,5 kg ha ${ }^{-1}$ de Roundup WG (glifosato) e 100 $\mathrm{mL} \mathrm{ha}^{-1}$ do inseticida Turbo ( $\beta$-ciflutrina). A adubação de cobertura foi realizada no dia 30 de novembro de 2013 , com a aplicação de $62 \mathrm{~kg} \mathrm{ha}^{-1}$ de $\mathrm{K}_{2} \mathrm{O}$, utilizando como fonte o cloreto de potássio.

O manejo fitossanitário com o fungicida Opera ${ }^{\circledR}$ (estrobirulina + triazol) foi realizado utilizando $600 \mathrm{~mL}$ e $500 \mathrm{~mL} \mathrm{ha}^{-1}$, mais óleo adjuvante $(5 \%$ do volume de calda) nos dias 4 e 20 de dezembro de 2013, respectivamente. Por ocasião da segunda aplicação de fungicida foi realizada a aplicação de $400 \mathrm{~mL} \mathrm{ha}^{-1}$ do inseticida Curyom ${ }^{\circledR}$ (profenofós + lufenuron) e $500 \mathrm{~mL}$ ha $^{-1}$ de Assist ${ }^{\circledR}$ (óleo mineral).

Durante a condução do experimento foram realizadas as seguintes avaliações em campo: índice de área foliar aos 38 e 73 dias após a semeadura (DAS), com auxílio do Ceptômetro ACCUPAR LP 80 e avaliação do número e espécies de plantas daninhas presentes nas parcelas aos 52 DAS, com o auxílio de armação de ferro com dimensões de 0,5 x $0,5 \mathrm{~m}$.

Após a colheita do experimento, foram separadas aleatoriamente 10 plantas por parcela e avaliados os fatores: altura de planta, altura da inserção da primeira vagem, número de vagens por planta e massa de 1000 grãos (BRASIL, 2009). A produtividade foi obtida a partir da massa seca dos grãos (13\% umidade), contidos na área útil de cada parcela mediante pesagem e expressa em quilogramas por hectare.

Os dados foram submetidos à análise de variância, e a significância dos quadrados médios obtidos na análise de variância foi testada pelo teste $\mathrm{F}$ ao nível de $5 \%$ e $1 \%$ de probabilidade. Os dados referentes às populações de plantas foram submetidos à análise de regressão calculada para equações lineares e quadráticas e foram aceitas as equações significativas até $5 \%$ de probabilidade pelo teste $\mathrm{F}$, com o maior coeficiente de determinação $\left(\mathrm{R}^{2}\right)$.

\section{Resultados e Discussão}

Não houve interação significativa, entre parcela e subparcela, para nenhuma das variáveis estudadas. Avaliando isoladamente o fator de variação subparcela, observa-se que houve efeito significativo apenas para as variáveis altura de plantas e índice de área foliar aos 73 DAS (LAI 2) (Tabela 2). Plantas cultivadas em espaçamento convencional apresentaram maiores valores quando comparadas às plantas semeadas em sistema de fileira dupla.

Os valores encontrados para produtividade não diferiram estatisticamente entre os sistemas de 
semeadura em fileira dupla e o convencional. Estes resultados demonstram o quanto a soja é adaptável a diferentes ambientes e sistemas.

Para altura de plantas, observou-se um crescimento linear conforme o aumento da densidade de semeadura (Figura 2A). Segundo Mauad et al. (2010), isso se explica pelo fato de que com o aumento da densidade de semeadura, aumenta também a competição intraespecífica por água, nutrientes e principalmente por luz, resultando no estiolamento das plantas. Komori (2004) observou que em plantios mais adensados houve um maior crescimento das plantas em relação aos menos adensados semeados no mesmo período. Quando ocorre maior competição entre as plantas, há menor disponibilidade de fotoassimilados para o crescimento vegetativo na forma de ramificações, pois são destinados preferencialmente para o crescimento da haste principal (MARTINS et al., 1999).

Tabela 2. Médias de altura de planta (AP), altura de inserção da primeira vagem (AIPV), número de vagens por planta (NVP), massa de 1000 grãos (M1000), índice de área foliar aos 38 e 73 DAS, (IAF38 e IAF73, respectivamente), radiação não interceptada pelo dossel aos 38 e 73 DAS (RID38 e RID 73, respectivamente) e produtividade de grãos (PROD)

\begin{tabular}{|c|c|c|c|c|c|c|c|c|c|}
\hline \multirow{2}{*}{$\begin{array}{l}\text { Arranjo Espacial } \\
\text { de plantas }\end{array}$} & $\mathbf{A P}$ & AIV & NVP & M1000 & IAF38 & RID38 & IAF73 & RID73 & PROD \\
\hline & $\mathbf{c m}$ & $\mathbf{c m}$ & un & $\mathbf{g}$ & & $\%$ & & $\%$ & $\mathrm{~kg} \mathrm{ha}^{-1}$ \\
\hline Fileira dupla & $87,89 \mathrm{~b}$ & 9,99 & 58,50 & 138,11 & 2,10 & 29 & $6,58 \mathrm{~b}$ & 3,8 & 3.543 \\
\hline Convencional & $90,85 \mathrm{a}$ & 10,55 & 54,40 & 136,37 & 2,20 & 25 & $6,98 \mathrm{a}$ & 3,1 & 3.644 \\
\hline $\mathrm{F}$ & $5,66^{*}$ & $2,59^{\mathrm{ns}}$ & $0,42^{\mathrm{ns}}$ & $1,10^{\mathrm{ns}}$ & $0,51^{\mathrm{ns}}$ & $1,22^{\mathrm{ns}}$ & $8,85^{* *}$ & $2,09^{\mathrm{ns}}$ & $1,13^{\mathrm{ns}}$ \\
\hline $\mathrm{CV}(\%)$ & 4,39 & 10,73 & 35,38 & 3,82 & 21,65 & 42,77 & 6,14 & 44,56 & 8,34 \\
\hline
\end{tabular}

${ }^{\text {ns }}=$ não significativo. $* \mathrm{e}^{* *}=$ significativo a 5 e $1 \%$ pelo teste $\mathrm{F}$, respectivamente.
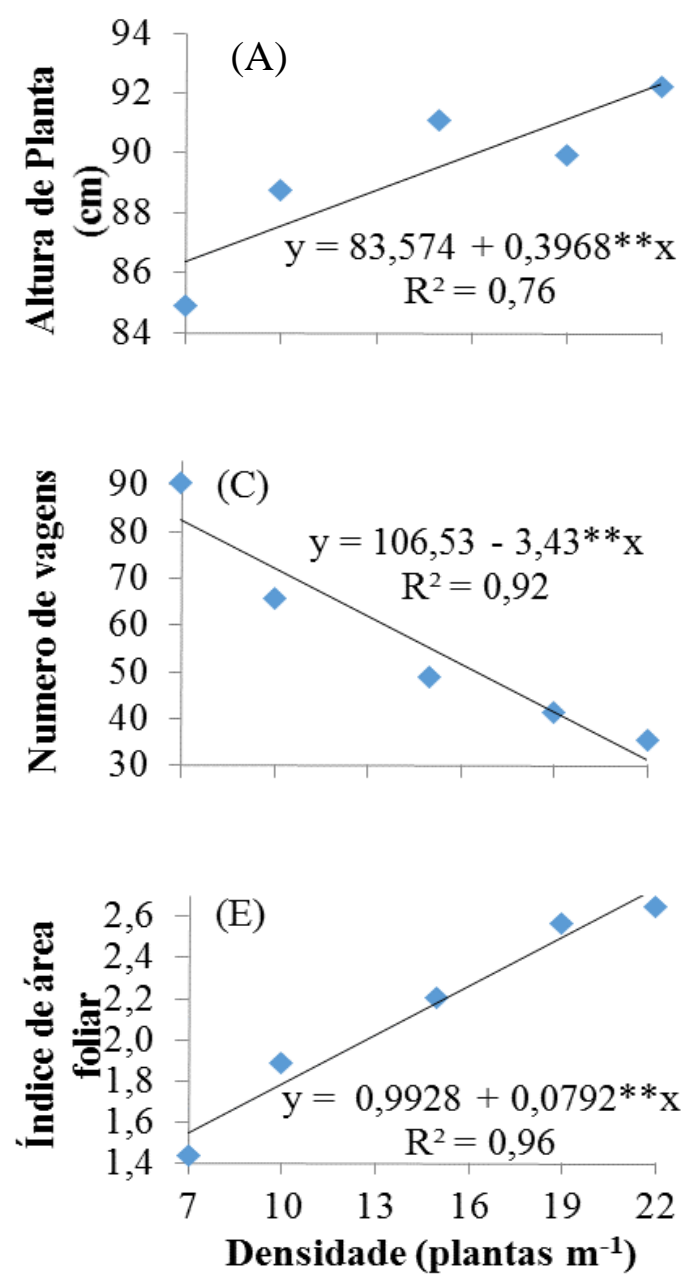
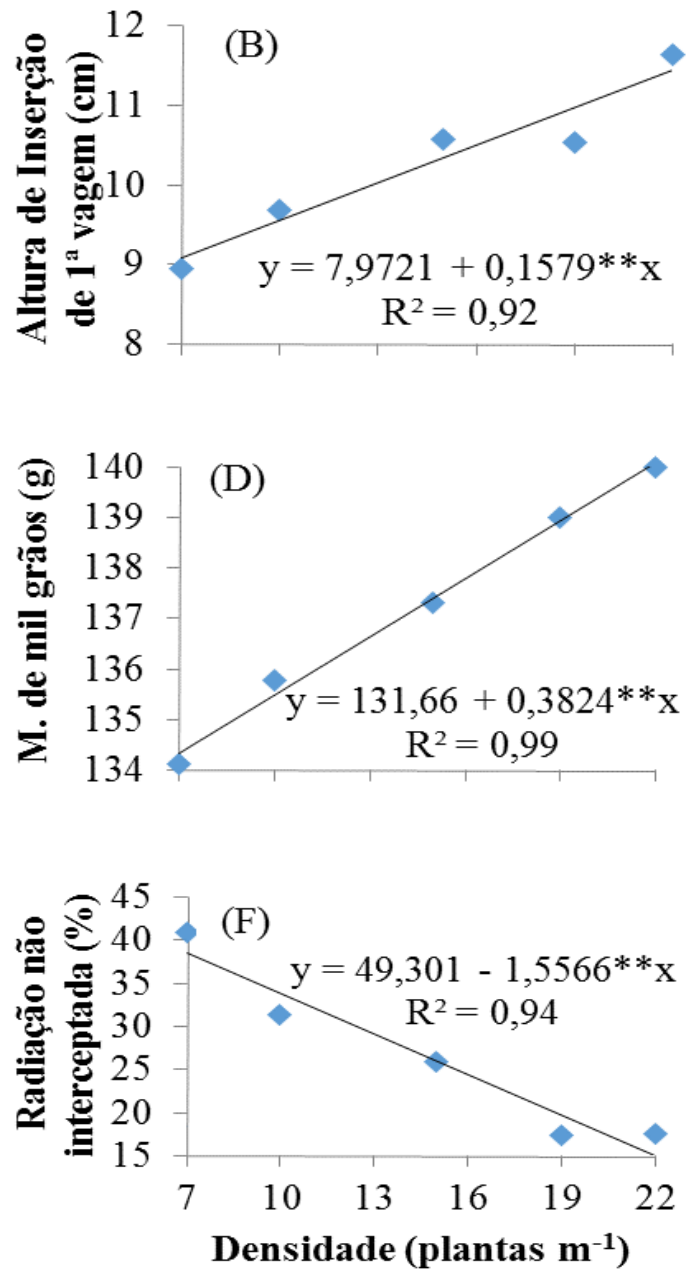

Figura 2. Alturas de plantas (A), altura de inserção da $1^{\text {a }}$ vagem (B), número de vagens por planta (C), massa de 1000 grãos (D), índice de área foliar (E) e radiação não interceptada pelo dossel (F) da soja, em função da densidade de semeadura. 
Houve aumento linear da altura de inserção da primeira vagem em função do aumento da densidade de semeadura (Figura 2B). Essa altura é medida para definir se a planta é apta para a colheita mecanizada. Para Sediyama et al. (1999), a altura ideal para a inserção da primeira vagem é entre $10 \mathrm{e} 12 \mathrm{~cm}$ para que não haja perda na colheita em solos planos, e no mínimo $15 \mathrm{~cm}$ para solos de topografia inclinada, devido à altura da plataforma de corte. Somente a partir da densidade de 15 plantas $\mathrm{m}^{-1}$ ocorreu altura de inserção de vagem ideal para a colheita mecanizada.

Mauad et al. (2010) relatam que essa característica da planta é de grande importância para a regulagem da colhedora evitando perdas. Estes autores também observaram aumento linear para este componente em função do aumento da densidade de plantas.

Para o número de vagens por planta, houve um efeito linear negativo em função do aumento da densidade de semeadura (Figura 2C). Este resultado está associado aos dados de altura de plantas apresentados anteriormente, uma vez que plantas mais altas tendem a apresentar menor número de ramificações. Tourino et al. (2002) também observaram que o número de vagens por planta foi reduzido à medida que se aumentou a densidade de plantas.

Para massa de mil grãos, ocorreu aumento linear acompanhando o aumento da densidade de semeadura (Figura 2D). Tourino et al. (2002) relatam que a massa de 1000 grãos aumenta com a o aumento da densidade de plantio porque o número de vagens por plantas (drenos fisiológicos) diminui, havendo assim menor competição por fotoassimilados que são concentrados em um menor número de grãos.

Houve aumento no índice de área foliar com o aumento da população de plantas (Figura 2E). Isso se deve ao maior número de plantas na linha, principalmente nos estádios iniciais de desenvolvimento da cultura em que a parte aérea ainda não sofreu influência dos tratamentos. Na segunda avaliação, aos 73 DAS, não houve ajuste de regressão, linear ou quadrática, para os resultados obtidos. Este comportamento pode ser explicado pelo fato das plantas em menores densidades terem emitido maior número de ramos, resultando na compensação do índice de área foliar.Com o aumento da densidade de semeadura houve redução da radiação não interceptada (Figura $2 \mathrm{~F}$ ). Isso se deve ao fato de que com o aumento da densidade de plantas ocorre aumento do índice de área foliar.

Verificou-se aumento da produtividade à medida que se aumentou a população de plantas. Esse aumento está relacionado a dois fatores: ao número de vagens por planta à massa dos grãos produzidos (Figura 3).

Embora o número de vagens por planta tenha diminuído com o aumento da densidade de semeadura (Figura 2C), o maior número de plantas proporcionou maior número de vagens por hectare. Multiplicando-se o número de vagens por planta pelo número de plantas por metro obtêm-se 781,9 e 633,8 vagens por metro, respectivamente na maior e menor população. Resultado diferente foi encontrado por Tourino et al. (2002), utilizando a cultivar CAC-1, as parcelas com menores densidades $\left(10\right.$ plantas $\left.\mathrm{m}^{-1}\right)$ produziram mais que as parcelas com densidades de plantas mais elevadas (22 plantas $\mathrm{m}^{-1}$ ), por conseguirem expressar melhor o potencial produtivo de cada planta ao ponto de superar o maior número de plantas na linha.

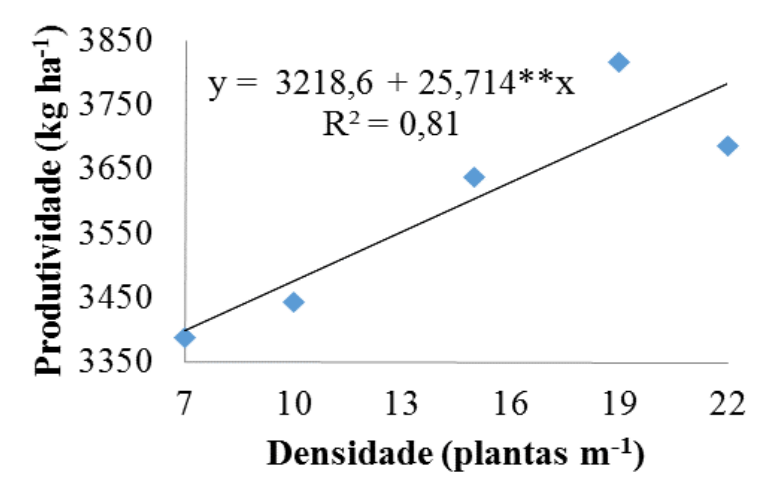

Figura 3. Produtividade de grãos de soja em função da densidade de semeadura.

\section{Conclusões}

$\mathrm{O}$ arranjo espacial em fileiras duplas resulta na alteração da arquitetura das plantas de soja reduzindo a estatura da lavoura.

$\mathrm{O}$ arranjo espacial em fileiras duplas não interfere na produtividade de grãos de soja.

$\mathrm{O}$ aumento da densidade de semeadura eleva a produtividade de grãos da soja independente do arranjo espacial entre plantas.

\section{Referências Bibliográficas}

ARGENTA, G.; SILVA, P.R.F.; SANGOI, L. Arranjo de plantas em milho: análise do estado-da-arte. Ciência Rural, Santa Maria-RS, v.31, n.6, p.1075-1084, 2001.

BRACHTVOGEL, E.L.; PEREIRA, F.R.S. da; CRUZ, S.C.S.; BICUDO, S.J. Densidades populacionais de milho em arranjos espaciais convencional e equidistante entre plantas. Ciência Rural, Santa Maria-RS, v. 39, n.8, p. 2334-2339, 2009.

BRASIL. MINISTÉRIO DA AGRICULTURA E DA REFORMA AGRÁRIA. Secretaria Nacional de Defesa Agropecuária. Departamento de Defesa Vegetal. Coordenação de Laboratório Vegetal. Regras para análise de sementes. Brasília, DF, 2009. 395p.

BRUNS, H.A. Comparisons of Single-Row and Twin-Row Soybean Production in the Mid-South. Agronomy Journal Madison - WI, v.103, n. 3, p. 702-708, 2011. 
EMBRAPA. EMPRESA BRASILEIRA DE PESQUISA AGROPECUÁRIA. Sistema brasileiro de classificação de solos. 2.ed. Rio de Janeiro-RJ: Embrapa - SPI, 2006. 286 p.

EMBRAPA. EMPRESA BRASILEIRA DE PESQUISA AGROPECUÁRIA. Manual de análises químicas de solos, plantas e fertilizantes. 2.ed. Brasília-DF: Informação Tecnológica, 2009. 628p.

KOMORI, E.; HAMAWAKI, O. T.; SOUZA, M. P.; SHIGIHARA, D.; BATISTA, A. M. Influência da época de semeadura e população de plantas sobre características agronômicas na cultura da soja. Bioscience Journal, Uberlândia-MG, v. 20, n. 3 p. 13-19, 2004.

MARTINS, M. C.; CÂMARA, G. M. S.; PEIXOTO, C. P.; MARCHIORI, L. F. S.; LEONARDO, V.; MATTIAZZI, O. Épocas de semeadura, densidades de plantas e desempenho vegetativo de cultivares de soja. Scientia Agrícola, Piracicaba-SP, v. 56, n. 4, p. 851-858, 1999.

MAUAD, M.; SILVA, T. L. B.; ALMEIDA NETO, A. I.; ABREU, V. G. Influência da densidade de semeadura sobre características agronômicas na cultura da soja. Revista Agrarian, Dourados-MS, v. 3, n. 9, p. 175-181, 2010.
PIRES, J. L. F.; COSTA, J. A.; THOMAS, A. L. Rendimento de grãos de soja influenciado pelo arranjo de plantas e níveis de adubação. Pesquisa Agropecuária Gaúcha, Porto AlegreRS, v.4, n. 2, p.183-188, 1998.

PIRES, J. L. F.; COSTA, J. A.; THOMAS, A. L.; MAEHLER, A. R. Efeito de populações e espaçamentos sobre o potencial de rendimento da soja durante a ontogenia. Pesquisa Agropecuária Brasileira, Brasília-DF, v. 35, n. 8, p. 1541$1547,2000$.

SEDIYAMA, T.; TEIXEIRA, R.C.; REIS, M.S. Melhoramento da soja. In: BORÉM, A. (ed). Melhoramento de espécies cultivadas. Viçosa-MG: UFV, 1999. p.478-533.

TOURINO, M.C.C.; REZENDE, P.M. de; SALVADOR, N. Espaçamento, densidade e uniformidade de semeadura na produtividade e características agronômicas da soja. Pesquisa Agropecuária Brasileira, Brasília-DF, v. 37, n. 8, p. 10711077, 2002. 